\title{
Incidence of Tuberculosis among Human Immunodeficiency Virus (HIV) patients attending General Hospital Bajoga
}

\author{
Wasa Alibe Ahmed ${ }^{1}$, Raj Kumar Prajapati ${ }^{2}$ and Bello Y. Bilkisu ${ }^{3}$ \\ ${ }^{123}$ Department of Biological Sciences, Gombe State University, P. M. B 127 Gombe
}

\begin{abstract}
Incidence of tuberculosis (TB) among patients attending Voluntary counseling and Testing (VCT) clinic at General Hospital Bajoga was determine in order to provide data on the disease burden and suggest ways on controlling the infection if present. A total of 304 HIV sero-positive patients from January to June 2013 were screened for TB. The study revealed 98 (32.2\%) were TB positive, of which $63(64 \%)$ were males, while 35 $(36 \%)$ were females. The highest incidence rate of 47 was seen in the 16-35years age group, followed by 44 observed in the above 35years age group. The less than 15 years age group has the least incidence rate of 7. Retrospective studies conducted from 2010-2012 also revealed a prevalence rate of 52 (15.1\%) in 2010, 24 (5.6\%) in 2011 and 31 (7.1\%).
\end{abstract}

Key words: Incidence, Gender, Tuberculosis, Retrospective, HIV

\section{Introduction}

Tuberculosis is a global public health problem, although curable is the leading cause of HIV related illness and death. Tuberculosis and HIV have been closely linked since the emergence of AIDS (Raviglione et al., 1997). Data from World Health Organization ( WHO) shows that tuberculosis is the most common cause of death from infectious diseases, causing more death than HIV and malaria combined; it is common in eastern Europe, south east-Asia and sub-Saharan Africa. One-third of the world is infected with tuberculosis, with Africa harbouring about $29 \%$ of those infected. However only about $5-10 \%$ of those infected develops the disease, and become infectious at some time in their life.

It is a global health priority being a killer disease that manifests in its pulmonary form in up to $70 \%$ of cases or as extra pulmonary affecting all parts of the body (Harries et al., 1996). An estimated seven million new cases occur each year, resulting in $2-3$ million deaths despite being curable and preventable with effective treatment regimens and vaccines (WHO, 2005). Improvement in case identification and compliance with appropriate treatment remains a major challenge (WHO, 2005). The World Health Organization (WHO) estimates that one-third of the World population is infected with Mycobacterium tuberculosis resulting in an estimated 8 million new cases of T.B and nearly 2 million deaths each year. Furthermore, approximately 10 million people are estimated to be co-infected with TB and HIV, and over $90 \%$ of these dully infected individuals reside in developing nations. In sub-Saharan Africa (Nigeria inclusive) the rates of co-infection exceeds 1000 per 100,000 populations. A retrospective study carried out in Kaduna State from 2008 - 2009 involving 2,187 registered HIV positive patients, at a clinic showed $29 \%$ prevalence of co-infection rates.

The general consensus among scholars Worldwide is that there is a link between Tuberculosis and HIV/AIDS. This agreement is as a result of similar conclusions reached from findings of various studies conducted both in the developed and developing countries (WHO, 2005; Elliot et al., 1990). In Nigeria, although incidences of Tuberculosis predate that of HIV/AIDS, reported cases of pulmonary tuberculosis have been on the increase since 1986 when the first case of AIDS was identified and reported.

The high prevalence rate of HIV and Tuberculosis in Gombe State necessitates this study. This is especially true of Bajoga, a town where Ashaka Cement Factory is located is a place famous as a hot spot for HIV carriers due to the presence of long journey trailer drivers.

Thus the choice of the General Hospital Bajoga as a case study area for collection of data on the coinfection rate of HIV and TB among patients attending the hospital is therefore appropriate and justified.

Furthermore, although there are confirmed linkages between Tuberculosis and HIV, it has been observed that the nature and association varies from location and ethnic groups (Eliot et al., 1990). Consequently therefore, in a country like Nigeria with large geographical spread, high population, and inadequate resources there is need for more localized studies in order to establish the nature and magnitude of the observed relationship that are location specific for effective clinical management.

This study is therefore aimed at conducting a retrospective study of the rate of prevalence of TB among HIV/AIDS patients attending General Hospital BAJOGA. It is hoped that findings would assist the clinicians in the management of $\mathrm{TB} / \mathrm{HIV}$ related cases in this community and environs. 


\subsection{Study Area}

\section{Materials and Methods}

The study was conducted in Bajoga, Funakaye L.G.A Gombe State from January to June, 2013.

\subsection{Study Population}

The populations used for the study are HIV positive patients attending Voluntary Counseling and Testing (VCT) clinic at General Hospital Bajoga. Eligible subjects are those whose consent are received and have agreed to participate in the study.

\subsection{Sample Collection}

Sputum samples were collected aseptically from three hundred and four (304) patients in a plastic leakproof container and sent to the TBL laboratory for analysis. Retrospective data from 2010-2012 was also collected for comparison and further analysis (Cheesbrough, 2006).

\subsection{Sample analysis}

Sputum samples were processed and stained using the ziehl Neelson staining technique and viewed under the microscope for acid fast bacilli as described by Cheesbrough (20006)

\section{Results}

The result of the study carried out from January-June 2013 indicates that from the 304 samples screened, $98(32.2 \%)$ where TB positive out of which $63(20.7 \%)$ were males and $35(11.5 \%)$ were females as shown in Table 1.

Incidence rate based on age range is shown in Table 2. Highest rate of 47 was seen is age group 16-35, followed by 44 observed in $>35$ age group, while age group $0-15$ was 7 .

Retrospective incidence of TB and HIV co-infection patients from 2010-2012 is shown in Table 3. The result indicated that 52 were positive in 2010, 24 in 2011 and 31 in 2012. A total of 107 positive cases were registered.

The summary of TB and HIV co-infection cases from 2010-June, 2013 is shown in Table 4. For 2010, 345 persons were screened, 52 (15.1\%) were positive, while 293 (84.9\%) were negative. For 2011, 428 persons were screened, $24(5.6 \%)$ were positive, while 404 (94.4\%) were negative. For 2012, 439 persons were screened, 31 (7.1\%) were positive, while 408 (92.9\%) were negative. From January - June, 2013, 304 persons were screened, $98(32.2 \%)$ were positive, while $206(67.8 \%)$ were negative

Table 1: Incidence of HIV and Tuberculosis co-infection cases based on sex from the month of January June, 2013

\begin{tabular}{ccccc}
\hline & \multicolumn{2}{c}{ Sex } & Total \\
\hline Month & Male & Female & 15 \\
January & 10 & 5 & 11 & 28 \\
February & 8 & 3 & 11 & 17 \\
March & 14 & 14 & 6 & 16 \\
April & 5 & 4 & 98 \\
May & 13 & 3 & 35 & 98 \\
June & 13 & 63 &
\end{tabular}

Key: Total number of persons screened is 304

Table 2: Incidence of HIV and Tuberculosis co-infection cases based on age from the month of January June, 2013

\begin{tabular}{ccccc}
\hline & \multicolumn{3}{c}{ Age range (years) } & Total \\
Month & $0-15$ & $16-35$ & 7 & 15 \\
January & 2 & 6 & 9 & 11 \\
February & 1 & 1 & 12 & 28 \\
March & 2 & 14 & 1 & 1 \\
April & 0 & 10 & 7 & 17 \\
May & 1 & 9 & 8 & 16 \\
June & 1 & 7 & 44 & 98 \\
\hline Total & 7 & 47 &
\end{tabular}

Key: Total number of persons screened is 304 
Table 3: Retrospective incidence of HIV and tuberculosis co-infection Cases in General Hospital Bajoga from $2010-2012$

\begin{tabular}{|c|c|c|c|c|c|c|c|c|c|c|c|c|c|c|c|c|c|c|c|c|c|c|c|c|c|}
\hline & \multicolumn{2}{|c|}{ Jan. } & \multicolumn{2}{|c|}{ Feb. } & \multicolumn{2}{|c|}{ Mar. } & \multicolumn{2}{|c|}{ Apr. } & \multicolumn{2}{|c|}{ May. } & \multicolumn{2}{|c|}{ Jun. } & \multicolumn{2}{|c|}{ Jul. } & \multicolumn{2}{|c|}{ Aug. } & \multicolumn{2}{|c|}{ Sep. } & \multicolumn{2}{|c|}{ Oct. } & \multicolumn{2}{|c|}{ Nov. } & \multicolumn{2}{|c|}{ Dec. } & \multirow[t]{2}{*}{ Total } \\
\hline & $\mathrm{F}$ & $\mathrm{M}$ & $\mathrm{F}$ & $\mathrm{M}$ & F & M & F & $\mathrm{M}$ & $\mathrm{F}$ & $\mathrm{M}$ & $\mathrm{F}$ & $\mathrm{M}$ & $\mathrm{F}$ & $\mathrm{M}$ & F & $\mathrm{M}$ & $\mathrm{F}$ & $\mathrm{M}$ & $\mathrm{F}$ & $\mathrm{M}$ & $\mathrm{F}$ & $\mathrm{M}$ & $\mathrm{F}$ & $\mathrm{M}$ & \\
\hline 2010 & 3 & 2 & 2 & 4 & 4 & 3 & 2 & 2 & 1 & 1 & 2 & 3 & 1 & 2 & 2 & 0 & 1 & 4 & 1 & 5 & 0 & 4 & 1 & 2 & 52 \\
\hline 2011 & 0 & 2 & 1 & 0 & 2 & 1 & 0 & 0 & 1 & 1 & 2 & 2 & 1 & 2 & 1 & 0 & 1 & 1 & 0 & 0 & 2 & 2 & 1 & 1 & 24 \\
\hline 2012 & 0 & 5 & 1 & 1 & 2 & 2 & 0 & 2 & 0 & 2 & 0 & 3 & 0 & 2 & 1 & 1 & 1 & 1 & 3 & 2 & 1 & 0 & 1 & 3 & 31 \\
\hline Total & 3 & 9 & 4 & 5 & 8 & 6 & 2 & 4 & 2 & 4 & 4 & 8 & 2 & 6 & 4 & 1 & 3 & 6 & 4 & 7 & 3 & 6 & 3 & 6 & 107 \\
\hline
\end{tabular}

Key: $\quad$ F: female, M: male

Table 4: Summary of HIV and Tuberculosis co-infections cases

\begin{tabular}{lccc}
\hline & Total number screened & Positive cases (\%) & Negative cases (\%) \\
\hline 2010 & 345 & $52(15.1)$ & $293(84.9)$ \\
2011 & 428 & $24(5.6)$ & $404(94.4)$ \\
2012 & 439 & $31(7.1)$ & $408(92.9)$ \\
2013 (Jan-June) & 304 & $98(32.2)$ & $206(67.8)$ \\
\hline Total & 1516 & $205(13.5)$ & $1311(86.5)$ \\
\hline
\end{tabular}

\section{Discussion}

The present study (January-June, 2013) showed that the prevalence of Tuberculosis in HIV positive patients is $32.2 \%$. This is similar to $37.5 \%$ observed from studies carried out in Benin City, Edo State by Uche and Alozie (2004). Other Reports of similar studies although not from TB hospitals ranged from $12.0 \%$ in Ile-Ife (Onipede et al., 1999), 10.5\% and 14.9\% among children and adults respectively in Sagamu (Daniel et al., 2005), 10.8\% in Irrua (Nwobu et al., 2004), 6.1\% among those aged 20-40 years in Jos (Anteyi et al., 1996), $23.6 \%$ at Nguru (Yusuph et al., 2005), 4.2\% in Oyo and 35.1\% in Benue States (Odaibo et al., 2006). Others reported 28.12\% in Ibadan (Ige et al., 2005), 19.0\% in a semi arid region of Nigeria (Moses et al., 2003) and $16.6 \%$ in Delta state in a population suspected of TB and HIV (Jemikalajah and Okogun, 2009). This high prevalence rate could likely be attributed to the poor or low standard of living, poor standard of hygiene and bad sanitary habits as practiced by most inhabitants of Bajoga town. The low standard of living is believed to be one of the risk factors for the development of tuberculosis.

From the $98(32.2 \%)$ positive cases observed in this study it was observed that $63(64 \%)$ were males while $35(36 \%)$ were females. This result showing males more prone to co-infection may be as a result of the life style of the people as males tend to interact with each other unlike females who are mostly restricted to staying at home.

It was also observed that the highest prevalence rate of 47 was seen in the 16-35 years age group, followed by 44 seen in the above 35 years age group. While the lowest rate of 7 was seen in the less than 15 years age group. The prevalence of tuberculosis was higher in males than in females in both the HIV seropositive and HIV sero-negative subjects. This is in contrast with studies carried out in Europe, North America, and in Uganda where the prevalence rate was higher in females than in males. This trend was found to be highest in the age group of between the ages of 22 and 40 years. This increased prevalence may be due to the fact that persons of these ages are more sexually active, usually with more than one partner, and indulge in the consumption of alcohol and smoking. These habits lead to reduced immunity causing these persons to develop tuberculosis more easily. The higher prevalence of tuberculosis recorded in the males is due to the fact that males are more involved in these habits in Bajoga than females.

This high incidence rates indicates that TB and HIV still remains a burden in the society despite all measures taken to eradicate them.

Furthermore, retrospective studies carried out on TB- HIV co-infection from 2010-2012 showed the incidence rate of 52 in 2010, 24 in 2011 and 31 in 2012. This result is quite alarming. It also showed that there is an increase in the co-infection rate, i.e. $15.1 \%$ of persons screened in 2010 was positive, this figure reduced to $5.6 \%$ in 2011 but rose again to $7.1 \%$ in 2012 and so far $32.2 \%$ of those screened in 2013 were positive. The rapid increase in co-infection rate indicates that serious measures should be taken by the relevant authorities towards combating this menace.

\section{Conclusion}

From this study it is observed that Bajoga town in Funakaye LGA of Gombe State that is highly populated and harbours a lot of poor people of the society, show higher prevalence rates compared to other parts of Gombe North Senatorial District due to poverty, and the crowded nature of the area. Infection with human immunodeficiency virus (HIV) has been reported as an important risk factor for tuberculosis. Tuberculosis continues to occur and is the most common AIDS-associated opportunistic infection. In recent times, a lot of people who suffer from tuberculosis are also HIV sero-positive, it is therefore necessary that patients diagnosed 
to be HIV sero-positive should also be tested for Mycobacterium tuberculosis infection and be given preventive chemotherapy to prevent the development of active tuberculosis (TB). The youths and young adults should be educated adequately on how to prevent the HIV and tuberculosis infections. The urban areas of Bajoga should be decongested of the activities that attract people to the cities. More jobs should be provided for the youths in the rural areas as this will prevent rural -urban migration. This would reduce the transmission of tuberculosis due to congestion of people and would also improve the quality of life of the inhabitants of Bajoga metropolis and of the inhabitants of the rural areas.

\section{Acknowledgments}

We wish to acknowledge the management of General Hospital Bajoga for allowing us conduct the studies and providing us the necessary data. Not forgetting Prof. Abdullahi Mahdi the Vice Chancellor Gombe State University and Prof. A. G Ezra HOD, Department of Biological Sciences.

\section{References}

[1]. Anteyi, E.A., Idoko, J.A., Ukoli, C.O. and Bello, C.S. (1996) Clinical pattern of HIV in PTB in Jos Nigeria. Afr J Med Sci, 25(4):317-321

[2]. Cheesbrough Monica (2006). Medical Laboratory Manual for Tropical Countries Volume II. Printed in Great Britain at the University press Cambridge

[3]. Daniel, O.J., Salako, A.A., Oluwole, F.A., Alausa, O.K. and Oladapo, O.T (2005)HIV seroprevalence among newly diagnosed adult PTB patients in Sagamu. Nigerian J Med, 13(4): 393-397

[4] Elliott A.M, Luo. N. and Tembo. G (1990) Impact of HIV on tuberculosis in Zambia : a cross-sectional study, fir Med.I. 1990, 301, 412

[5] Harries A.D, Mbewe L.N.O, Salanifoni FML, Nyngulu DS, Randal JT Nunn P (1996) Tuberculosis Programme changes and treatment outcomes in patient with smear positive pulmonary tuberculosis in Blantyre, Malawi. Lancet 347: 807 - 809

[6] Ige, O.M., Sogaolu, O.M. and Ogunlade, O.A. (2005). Pattern of presentation of Tuberculosis and the hospital prevalence of Tuberculosis and Immunodeficiency virus co-infection in University College Hospital Ibadan: a review of five years (1999 - 2007).

[7] Jemikalajah, JSS.D. and Okogun, G.A.(2009). Health point prevalence of HIV and Pulmonary Tuberculosis among patients in various parts of Delta State, Nigeria. Saudi Med J. 30(3); $387-391$

[8] Moses, A.E., Adelowo, K.A. and Ajayi, B.B. (2003). Prevalence of HIV-1 infection among patients with Leprosy and Pulmonary Tuberculosis in a semi arid region, Nigeria. J R Soc Promot Hlth.123(2): 117 - 119

[9] Nwobu, G.O., Okodua, M.A. and Tatfeng, Y.M. (2004). Comparative study of HIV Associated Pulmonary Tuberculosis in Chest Clinics from Two Regions of Edo State, Nigeria. Online J Hlth Allied Scs. 2004;3:4 URL: http://www.ojhas.org/issue 11/2004-3$\underline{4 . h t m}$

[10] Odaibo, G.N., Gboun, M.F., Ekanem, E.E.,Gwarzo, S.N., Saliu, I., Egbewunmi, S.A., Abebe, E.A. and Olaleye, D.O. (2006). HIV infection among patients with PTB in Nigeria. African Journal of Medicine and Medical Sciences. 35:93-98

[11] Onipede, A.O., Idigbe, O., Ako-Nai, A.K., Omojola, O., Oyelese, A.O., Aboderin, A.O., Komolafe, A.O. and Wemambu, S.N.C ( 1999). Seroprevalence of HIV antibodies in TB patients in Ile-Ife. East Afr Med J.76(3): 127-132

[12] Raviglion MC, Harries AD, Wikiason D, Nunn P (1997) Tuberculosis and HIV current status in Africa. Afr Health (Supp): 115 123

[13] Uche, A. and Alozie, O. (2004) Emerging Prevalence of HIV among TB patients in Benin City, Nigeria. International Conference on AIDS. 2004, July 11-16; Abstract no. TUPeD5203, 2004

[14] World Health Organization Report (2005): Global tuberculosis control, surveillance, planning and financing: WHO/HTM/TB/2005, 369, Geneva, World Health Organization

[15] Yusuph, H., Lailani, S. B. and Ahedjo, A. (2005). Prevalence of HIV in TB patients in Nguru North Eastern Nigeria. Sahel Med.J. 2005: 8(3): 65-67 